\title{
Concepções de conhecimento escolar: potencialidades do Programa Institucional de Bolsa de Iniciação à Docência
}

\author{
Andréa Rosana Fetzner \\ Maria Elena Viana Souza \\ Universidade Federal do Estado do Rio de Janeiro
}

\section{Resumo}

Considerando-se as possibilidades abertas por meio do Programa Institucional de Bolsa de Iniciação à Docência (PIBID), o presente artigo discute as concepções de conhecimento escolar e os desafios de um projeto de transformação da escola básica em uma instituição que assuma perspectivas interculturais em relação ao conhecimento escolar. Nesse sentido, compreende-se que ainda é um desafio, para muitas escolas de ensino fundamental, reconhecer e trabalhar com conhecimentos que sejam significativos para a população que as frequenta. Apoiado pela CAPES, no âmbito do PIBID, este trabalho apresenta os resultados iniciais de um estudo sobre as concepções de conhecimento escolar que permeiam os saberes da docência de professores de escolas públicas e de bolsistas de iniciação à docência envolvidos no projeto. 0 desenvolvimento da pesquisa deu-se mediante o estudo da interculturalidade e de seus desafios contemporâneos, o acompanhamento trabalho desenvolvido nas escolas e a aplicação de questionários a estudantes bolsistas de iniciação à docência da Universidade Federal do Estado do Rio de Janeiro (UNIRIO), que desenvolvem um projeto por meio do referido programa. Observamos, até o presente momento, que a concepção de conhecimento escolar tem oscilado entre perspectivas conservadoras e perspectivas emancipatórias, sendo estas últimas entendidas como aquelas que, compartilhando do conceito de bem viver, procuram integrar-se às necessidades das comunidades e compartilhar de princípios que envolvem a relacionalidade, a correspondência e a complementariedade, tal como salienta Catherine Walsh.

\section{Palavras-chave}

Docência - Conhecimento escolar - Interculturalidade.

Correspondência:

Andréa Rosana Fetzner

akrug@uol.com.br 


\title{
Concepts of school knowledge: potentialities of the Institutional Program of Teaching Initiation Scholarships
}

\author{
Andréa Rosana Fetzner \\ Maria Elena Viana Souza \\ Universidade Federal do Estado do Rio de Janeiro
}

\begin{abstract}
Considering the possibilities resulting from the Institutional Program of Teaching Initiation Scholarships (PIBID), this paper discusses the concepts of school knowledge and the challenges of project to transform basic schooling into an institution that takes intercultural perspectives in relation to school knowledge. Thus, it is understood that it is still a challenge for many elementary/ intermediate schools, to acknowledge and work with knowledge that are significant for the people who attend it. Funded by CAPES, in the context of PIBID, this paper presents the early results of a study on the conceptions of school knowledge that intertwine the teaching practice of teachers from public schools and scholarship holders for teaching initiation involved in the project. The research was developed through the study of intercultural aspects and its contemporary challenges, the follow-up of the work done in the schools and the use of questionnaires to students who had a teaching initiation scholarship granted by the Federal University of the State of Rio de Janeiro (UNIRIO), which implemented a project by means of the above mentioned program. We found, until now, that the concept of school knowledge has oscillated between conservative and emancipatory perspectives, and the latter are understood as those which, sharing the notion of well-living, attempt to integrate themselves into the needs of the communities and to share principles involving relationality, the correspondence and the complementarity, as emphasized by Catherine Walsh.
\end{abstract}

\section{Keywords}

Teaching - School knowledge - Interculturality.

Contact:

Andréa Rosana Fetzner

akrug@uol.com.br 


\section{Interculturalidade como instrumento de análise das concepções de conhecimento}

A interculturalidade pode significar, como processo e projeto, o contato e o intercâmbio entre culturas, em termos equitativos e em condições de igualdade; por isso mesmo, trata-se, ainda, de um projeto que busca construir uma convivência de respeito e legitimidade entre todos os grupos da sociedade (WALSH, 2009). Na discussão aqui apresentada, entende-se que a legitimação de conhecimentos outros, na escola de ensino fundamental e médio, é ainda um grande desafio em cuja superação a interculturalidade pode contribuir.

Com frequência, desde fóruns de especialistas em educação até conversas com pais de estudantes das escolas de ensino fundamental, é comum ouvir a ideia de que o importante é aprender a ler, escrever e calcular, porque o resto poderia ser aprendido por meio dessas três habilidades. Pensar criticamente essa visão da função da escola permite problematizar este entendimento: será que aprender que o racismo, por exemplo, é uma construção histórica decorrente de interesses políticos, econômicos e culturais seria menos importante do que aprender a ler, escrever e calcular? Aprender a pensar sobre a relação entre sociedade e tecnologia em contextos diversos como a $2^{\text {a }}$ Guerra Mundial e o mundo contemporâneo é menos importante? Compreender os processos sociais e culturais que estão na base da produção de nossas condições de vida e de nossa relação com o ambiente é menos importante? Exercitar a criação coletiva de regras, o debate de princípios, o respeito a diferentes perspectivas religiosas é menos importante? $\mathrm{Ou}$, ainda, apenas a capacidade de ler, escrever e calcular possibilitaria desenvolvermos nosso entendimento intelectual sobre essas questões? Existiria um universalismo em ler, escrever e calcular, ou seja, ao aprender tais habilidades, aprenderíamos a aplicá-las em qualquer situação? Ler um poema é o mesmo que ler uma bula de remédio?
Por meio dessa percepção crítica da escola, é possível entendê-la como um espaço onde, para além da troca de saberes, constrói-se grande parte das bases afetivas de nossa dignidade e onde é possível erigir um projeto de sociedade calcado em valores como o respeito a si próprio e ao ser/outro.

Com base nesse entendimento, o conceito de interculturalidade pode possibilitar refletir sobre os conhecimentos escolares como suspeitos de servirem a interesses específicos, não sendo dotados de um universalismo que os credenciaria a serem tomados a priori ou acima de qualquer suspeita. Mais do que isso, a interculturalidade tem como foco a relação entre as diferentes culturas (de forma tensa e não necessariamente amorosa ou, menos ainda, folclórica) para a compreensão de como determinados saberes, valores e linguagens vão sendo colocados em um lugar superior a outros na sociedade e, em nossa análise, também na escola.

A interculturalidade pode ser entendida, ainda, como uma proposta democrática de diálogo de culturas sem interpretações binárias que oporiam uma à outra. Como afirma José Marín (2010), "um diálogo que nos permita construir um encontro benéfico entre culturas, onde uns aprendem com outros" (p. 323).

Se entendemos os conhecimentos escolares como conhecimentos em disputa (APPLE, 1989), talvez seja mais fácil possibilitar a discussão dos conteúdos trabalhados na escola de forma que eles possam ser mais significativos socialmente e contribuir mais para uma formação libertadora (FREIRE, 1972); com isso, é retomada a importância de ler, escrever e calcular como instrumento para entendermos a sociedade, e não como fim em si mesmo. A compreensão de tais habilidades como dotadas de uma finalidade intrínseca parece-nos facilitar abordagens tecnicistas dos fazeres escolares e colaborar para a desvinculação entre as questões O que fazer? Por que fazer? e a questão Como fazer?. Trata-se de perguntas que, por meio de um olhar crítico, orientam as discussões sobre currículo e suas relações com a didática. 
Neste estudo, a interculturalidade constitui-se em instrumento por meio do qual se analisa o trabalho com o conhecimento na formação docente. Entende-se ser possível a valorização de diferentes saberes, valores e linguagens presentes no cotidiano da escola, bem como a superação do desconhecimento, da desvalorização e/ou da subalternização a que, muitas vezes, estão submetidos alguns alunos.

Na educação, a interculturalidade leva-nos ao entendimento de que a participação nos processos de gestão, conhecimento e troca de saberes é imprescindivel para que os sujeitos envolvidos possam melhorar suas condições de vida, compreendendo melhor "nossas sociedades tão fragmentadas, para melhor assumir os conflitos culturais e religiosos que as caracterizam" (MARÍN, 2010, p. 323). A interculturalidade, como instrumento de análise, possibilita olhar para o Programa Institucional de Bolsa de Iniciação à Docência (PIBID) e para suas potencialidades no tratamento didático dos conhecimentos escolares, de forma a não apartar esses conhecimentos de suas perspectivas políticas, sociais e culturais.

\section{O PIBID como espaço de conhecimento e formação}

O PIBID, mantido pela Coordenação de Aperfeiçoamento de Pessoal do Ensino Superior (CAPES), em desenvolvimento na Universidade Federal do Estado do Rio de Janeiro (UNIRIO), por meio de projeto que tem como foco a qualidade e a valorização das práticas escolares, possibilitou a distribuição de bolsas de iniciação à docência a estudantes de licenciaturas, professores de escolas públicas e professores. 0 projeto aqui em discussão foi elaborado em uma universidade pública da Zona Sul do Rio de Janeiro e propõe a formação na docência de forma integrada às práticas de pesquisa, ou seja, o licenciando, os professores supervisores e os coordenadores de subprojeto desenvolvem a pesquisa sobre e com a docência, com a escola, em grupos de discussão que, desde uma perspectiva qualitativa e dialógica, abordam questões que se apresentam como problema no exercício da docência. Em tais reuniões, realiza-se o estudo de pesquisas referentes aos problemas vivenciados, a produção de propostas de ação, o debate sobre a aplicação das propostas e a reflexão sobre estas durante e após a aplicação. Em meio a esse processo, possibilidades e planejamentos, materiais didáticos e experiências são desenvolvidos.

Como possibilidade de potencialização do projeto em desenvolvimento, foram instalados fóruns para apresentação e discussão crítica dos trabalhos realizados - dentre estes, a Roda de Conversas, que teve sua primeira edição em dezembro de 2010. Foi nesse espaço que surgiu a preocupação sobre o que é tomado como conhecimento escolar e, por conseguinte, sobre quais experiências estamos desenvolvendo com a escola.

A pergunta da pesquisa surgiu quando percebemos que, em alguns momentos, o questionamento dos estudantes licenciandos bolsistas sobre o trabalho com a escola limitava-se a propor como fazer para que os alunos da escola aprendessem o que lhes era apresentado pela instituição, deixando de lado o questionamento sobre por que é isto que se deve aprender e não outra coisa. Assim, para além das conversas e debates com o grupo, propôs-se, em maio de 2011, a aplicação de um questionário que, complementariamente às observações ao projeto, pretendia ajudar-nos a refletir sobre como os bolsistas de iniciação à docência têm percebido o que é o conhecimento escolar, como são levados a trabalhá-lo nas escolas e como o conhecimento aprendido pelo bolsista no trabalho com a escola tem contribuído para sua formação profissional.

0 acompanhamento à escola básica em que um dos subprojetos de área desenvolve-se, as observações aos projetos em andamento e o questionário aplicado tiveram como foco a necessidade de percepção sobre como o conhecimento é identificado, definido e trabalhado pelos bolsistas, em dois niveis de percepção: (a) as relações entre os conhecimentos da prática escolar 
(presentes nas escolas) e (b) os conhecimentos acadêmicos propostos pela universidade.

Nas escolas públicas envolvidas no projeto, temos percebido o quanto, muitas vezes, os conhecimentos escolares são tomados como únicos e, por meio de únicas linguagens e atividades, operam no sentido da exclusão de outros saberes, experiências e conhecimentos, em geral, das classes populares. Ao excluir esses saberes, a escola exclui também seus portadores.

$\mathrm{Na}$ busca de uma compreensão mais plural da realidade, de sua produção e de seu significado, a interculturalidade constitui-se, portanto, em um movimento de recuperar saberes, experiências e linguagens geralmente negados na sociedade - e, neste caso, na escola -, tornando-se, neste trabalho, instrumento para análise das concepções de conhecimento coletadas no questionário.

Ainda em relação à interculturalidade, é possível destacar a importância de se trabalhar com a temática racial, pois a grande maioria das crianças que estudam em escolas públicas é negra $^{1}$. A escola, em tese, deveria ser um lugar onde a igualdade de oportunidades fosse plenamente exercida. No entanto, a escola brasileira tem privilegiado as propostas curriculares que reproduzem valorizações comportamentais e conhecimentos que negligenciam as necessidades das crianças negras, que passam a ser a parte mais prejudicada da população escolar. Para romper com essa negligência, os conteúdos curriculares que tratam da história e da cultura afro-brasileira e africana deveriam ser valorizados e estarem fundamentados em princípios capazes de orientar para uma educação antirracista.

Das doze bolsistas que vivenciam suas experiências em uma escola de ensino fundamental, duas interessaram-se por trabalhar com o tema racial, realizando oficinas de contação de histórias e de confecção, pelas crianças, de bonecas Abayomi², e, ainda,

1- Crianças negras são aquelas consideradas, fenotipicamente, como pardas e pretas, conforme classificação do IBGE.

2- As bonecas Abayomi, de origem iorubá, significando aquele que traz felicidade ou alegria, são bonecas pretas, artesanais, elaboradas a partir de nós apresentando conhecimentos sobre a capoeira por meio de filmes e textos.

Essas propostas de trabalho vêm ao encontro do que é sugerido pelas Diretrizes Curriculares Nacionais para a Educação das Relações Étnico-Raciais e para o Ensino de História e Cultura Afro-Brasileira e Africana. Trata-se de uma política curricular que se apoiou em diversas áreas do conhecimento, buscando combater o racismo e a discriminação contra a população negra brasileira. Nesse sentido,

propõe a divulgação e produção de conhecimentos, a formação de atitudes, posturas e valores que eduquem cidadãos orgulhosos de seu pertencimento étnicoracial [...] para interagirem na construção de uma nação democrática, em que todos, igualmente, tenham seus direitos garantidos e sua identidade valorizada. (BRASIL, 2005, p. 10)

\section{A iniciação à docência e seus saberes}

Selma Pimenta e Maria do Socorro Lima (2010) propõem que a formação de professores seja compreendida como superação de uma formação apenas técnica e de uma formação apenas no âmbito de seus fundamentos teóricos; nesse sentido, entende-se o PIBID como um programa que oportuniza a vivência da iniciação no campo da docência em diálogo com a formação teórica oportunizada na universidade, desde, é claro, que tais campos estejam em postura de troca e não de sobreposição de saberes.

Entre os objetivos do projeto em desenvolvimento na universidade, além da integração teórico-prática da formação, encontram-se: (a) a necessidade de fixar estudantes de licenciatura no exercício da profissão e de aproveitar os saberes experienciais (GIMENO SACRISTÁN; PÉREZ GÓMEZ, 1998) dos profissionais já no exercício da profissão como participantes des-

em retalhos de pano, sem a utilização de cola ou costura e com pouquíssimo uso de ferramentas. Seus tamanhos variam entre $2 \mathrm{~cm}$ e 1,50 m. 
sa formação; (b) a oportunidade de inserção da instituição universitária na escola básica, em diálogo com esta sobre seus saberes, visando promover a formação profissional do professor em uma perspectiva integral. A partir desse ponto de vista, reconhecemos, portanto, que a escola e seus professores possuem experiências e saberes importantes de serem compartilhados com a universidade; esta, por sua vez, tem a necessidade de compartilhar suas pesquisas com a escola.

Mais especificamente na universidade em questão, o projeto vinculado ao PIBID tem-se caracterizado como projeto de pesquisa. São três subprojetos - licenciatura em ciências; pedagogia nos anos iniciais do ensino fundamental; e pedagogia na formação de professores em nivel médio - que oportunizam a vivência do mundo do trabalho de forma integrada ao levantamento de questões para estudo, possibilidades de articulação entre os saberes universitários e os saberes do campo de trabalho, problematização das questões pedagógicas que se apresentam no campo e elaboração de propostas voltadas a essas questões.

Nos três subprojetos, envolvem-se como bolsistas 36 estudantes de licenciatura (doze em ciências e 24 em pedagogia), seis professores de escola pública - coordenadores na escola (três escolas públicas envolvidas) -, três professores da universidade - subcoordenadores de área - e um professor coordenador geral do projeto. 0 desenvolvimento do projeto envolveu três escolas públicas de educação básica da cidade do Rio de Janeiro, sendo duas municipais e uma estadual.

Todos os bolsistas de graduação participam do cotidiano da escola pública, desenvolvem atividades ligadas ao ensino-aprendizagem e elaboram suas questões de pesquisa de forma integrada às demandas da escola. Na universidade, por sua vez, apresentam suas questões para discussão em diferentes disciplinas.

Durante o acompanhamento do projeto, percebemos que a docência passa a apresentar-se aos bolsistas de graduação como um campo de pesquisa, no sentido das possibilidades e dos desafios do cotidiano escolar. Propondo exercitar os princípios de uma educação libertadora, toma-se, como ponto de partida para o trabalho realizado, o diálogo entre estudantes e professores, entre os bolsistas do PIBID e seus coordenadores, e entre os estudantes da escola pública e os bolsistas do PIBID.

A busca do conteúdo programático, dos temas e estudos a serem realizados dá-se coletivamente, o que, segundo Paulo Freire (1972), exige uma nova educação expressada em uma nova escola, voltada para fomentar perspectivas de mundo, de humanização e de aprendizagem que se tornem possíveis no momento atual, perspectivas estas a que o autor contrapõe as perspectivas escolares por ele denominadas de educação bancária.

Dentre os 36 bolsistas do PIBID, responderam ao questionário no prazo solicitado quatro bolsistas do subprojeto de pedagogia nos anos iniciais do ensino fundamental, oito bolsistas do subprojeto de licenciatura em ciências e nove bolsistas do subprojeto de pedagogia na formação de professores em nivel médio, perfazendo 21 bolsistas. Desses 21, apenas dois possuem menos de dois meses no projeto e 19 possuem entre nove e doze meses (dados de maio de 2011), o que demonstra que os subprojetos estão com pouca rotatividade de bolsistas.

No subprojeto de pedagogia nos anos iniciais do ensino fundamental, os quatro bolsistas desempenham o mesmo tipo de ação: participam de aulas comuns e desenvolvem oficinas no contraturno da escola, buscando colaborar com as crianças que são indicadas por seus professores como estudantes com baixo desempenho escolar. Segundo os professores da escola, o baixo desempenho escolar é resultado, principalmente, de dificuldades na leitura e na escrita, na resolução de problemas matemáticos e nas quatro operações. Nem sempre as bolsistas concordam que as crianças tenham tais dificuldades, e muitas vezes percebem que os problemas referem-se mais ao relacionamento com colegas e professores, a timidez e baixa autoestima. Essas oficinas são planejadas com a professora co- 
ordenadora do subprojeto e acompanhadas, na escola, pelas professoras supervisoras.

Ao serem questionadas sobre quais conhecimentos de sua formação profissional mais contribuiriam para o trabalho que desempenham na escola, as bolsistas do subprojeto de pedagogia nos anos iniciais do ensino fundamental indicaram: estudos sobre o conceito de interação, mediação e zona de desenvolvimento proximal, de Lev Vygotsky; dentre os autores que mais colaboram com suas práticas, foram citados, além de Vygotsky, Paulo Freire e Vitor Paro; ainda, de forma genérica, elas mencionaram conhecimentos da área de didática e conhecimentos decorrentes da própria prática nas oficinas. 0 depoimento a seguir, da bolsista $\mathrm{C} 1^{3}$, resume esse aspecto:

Todos os textos que lemos, aulas a que assistimos e as experiências que temos se encontram nos momentos de atuação [na escola básica], em rede de saberes que é tecida a cada leitura e a cada conversa. Mais abertamente, influenciam na minha atuação na escola as reflexões acerca da avaliação e do currículo da escola. Currículos oficiais, ocultos, praticados e todos os observados estão em constante destaque quando circulamos no espaço escolar. Mais fundamentais para a minha prática se mostram também os textos sobre estágio supervisionado e as reuniões dos estagiários com seus supervisores na universidade. Os textos discutidos nas reuniões de pesquisa e as apresentações a que assistimos em congressos, todos versando sobre estudos do cotidiano, são extremamente importantes para a fundamentação de uma metodologia de pesquisa que consiste em um mergulho na escola. (Depoimento, maio 2011)

Por meio do depoimento citado, representativo do conjunto das falas que foram coletadas, é possível observar que saberes e espaços

3 - Os nomes das/os bolsistas foram substituídos por letras e números, buscando preservar 0 anonimato. de formação são articulados por demandas que as práticas na escola provocam e que emergem dos debates dos textos sugeridos para leitura.

No conjunto dos quatro depoimentos desse subprojeto, surge a ideia de que, para aprender, é preciso fornecer aos estudantes espaço para perguntas, questionamentos e para a autonomia na organização; além disso, os depoimentos indicam uma aprendizagem significativa realizada por meio do projeto e aprofundada nos estudos de graduação.

No trecho citado, a interculturalidade aparece no aguçamento para perceber as nuances dos currículos (currículos oficiais, ocultos e praticados) mencionados pela licencianda bolsista, o que demonstra a presença integrada da concepção ao olhar para a escola e para a própria formação.

Ao ser questionada sobre o que o PIBID representaria em sua formação profissional, a bolsista L2 apresentou depoimento representativo do conjunto das respostas obtidas:

0 PIBID proporcionou-me uma visão real do cotidiano escolar, possibilitoume experimentar novos métodos de ensino e diversas formas de mediação, de acordo com a necessidade de cada aluno. (Depoimento, maio 2011)

De forma geral, as bolsistas do subprojeto pedagogia nos anos iniciais do ensino fundamental identificam no PIBID um modo de experienciar novas formas de atuar no ambiente escolar e destacam a importância dessas novas formas de atuar (expressão utilizada pelas bolsistas) para a melhoria da aprendizagem dos estudantes envolvidos nas oficinas oferecidas na escola.

Essas novas formas de atuar no ambiente escolar, muito debatidas em várias disciplinas do curso de pedagogia, foram percebidas mais fortemente quando surgiu a dúvida entre o que seria reforço $o^{4}$ e o que seria oficina. Foi elaborada pelo grupo a definição de reforço

4 - Os professores da escola que participavam do projeto, de início, solicitaram que fossem reforçados os conteúdos trabalhados em sala 
como assistência aos alunos em relação às atividades e aos conteúdos desenvolvidos em sala de aula e aos trabalhos a serem feitos em casa. Em oposição à ideia de reforço, foram propostas as oficinas como atividades pedagógicas desenvolvidas considerando-se os mais variados interesses das crianças, suas vivências culturais, alguns conteúdos trabalhados em sala de aula e, ainda, a construção de uma autoestima positiva que traria novas formas de ver e de se relacionar com as pessoas.

Os bolsistas do subprojeto licenciatura em ciências desenvolvem seu trabalho na escola oferecendo oficinas voltadas ao ensino de ciências, focadas em horta, sustentabilidade e astronomia. Nesse grupo de trabalho, as temáticas das atividades estão previamente delimitados, ou seja, não decorrem do cotidiano da escola, mas de uma proposta de atividade do subprojeto na escola. Os enfoques estão relacionados à proposta de ensino de ciências das diretrizes curriculares nacionais para a área e são desenvolvidos nos anos finais do ensino fundamental e na educação de jovens e adultos.

Ao serem questionados sobre quais conhecimentos da formação na universidade mais têm contribuído com o desenvolvimento do trabalho na escola, sete bolsistas citaram, de forma geral, o domínio dos conteúdos a serem abordados em sala de aula e as contribuições de disciplinas como didática e psicologia para o entendimento do comportamento dos estudantes, do "processo de aprendizagem" e de que "alunos diferentes podem ter necessidades diferentes" (Depoimento do bolsista A, maio 2011). Apenas um dos bolsistas identificou a necessidade de trabalhar, no cotidiano da escola, com questões mais gerais a respeito das ciências:

Tenho um prazer enorme de falar de ciências [...], de personalidades históricas (grandes cientistas), todo um engajamento sociológico, educação ambiental e muito de documentários. Todas as disciplinas

de aula. Somente passaram a acreditar nesse tipo de trabalho após os resultados positivos apresentados para as crianças que dele participaram. escolares, costumo inserir alguns temas e acredito que uma visão ampla e geral de todas as ciências influencia mais na formação desses garotos [da escola] do que um conteúdo focado num tema só. (Depoimento do bolsista F, maio 2011)

A forma como os bolsistas desse subprojeto têm percebido o conhecimento de ciências indica certo isolamento da área em relação ao contexto do programa de ensino da escola e merece ser mais bem investigada no sentido de avaliar se se trata de uma dinâmica historicamente presente ao final do ensino fundamental - há muito tempo criticada, referindo-se à fragmentação dos conteúdos escolares - ou se isso diz respeito apenas à percepção dos bolsistas em relação ao conteúdo que trabalham. Destacamos o depoimento do bolsista F, por este ter demonstrado certa preocupação com uma formação geral dos estudantes, o que pode indicar uma perspectiva mais integrada dos conhecimentos de ciências com a relação de ensino-aprendizagem na escola.

Ao serem questionados sobre o que representa o PIBID para sua formação profissional, os bolsistas do subprojeto licenciatura em ciências indicaram que o projeto tem sido um laboratório da profissão de professor, oportunizando aprender "coisas que só aprendemos na prática docente, no dia a dia com os alunos" (Depoimento do bolsista A, maio 2011).

Os depoimentos, no que concerne a essa questão, não vincularam as aprendizagens advindas da universidade com as aprendizagens envolvidas na prática da docência na escola, o que pode ser mais um indicativo dos limites da formação oferecida, uma vez que não houve, nessas respostas, um vínculo espontâneo dos bolsistas entre o que é aprendido no espaço de formação acadêmica e o que é aprendido no espaço de formação na escola.

Os dois espaços (universidade e escola) são diferentes; todavia, por parte da universidade, há uma intencionalidade de integração da formação, sem dicotomia entre teoria e práti- 
ca, uma vez que ambas precisam ser refletidas por meio das aprendizagens da docência. Sendo assim, escola e universidade seriam espaços de formação teórico-prática.

Um dos oito bolsistas que respondeu ao questionário destacou, nessa questão, o que representaria o PIBID para sua formação e o caráter de financiamento do estudo:

[...] o simples fato de eu não precisar trabalhar à noite para ter o direito de estudar é de um enorme valor. 0 estudante de hoje, da biologia, precisa ter slides, tirar inúmeras xerox e principalmente ter os livros, se locomover e se alimentar [...], tudo isso exige um nível de classe média onde os pais bancam ou o aluno trabalha. Estudando integralmente isso é inviável e, no meu caso, só o simples fato de participar da escola, sentir a alegria dos alunos, montar minhas aulas, e conseguir me manter estudando tem um valor inexplicável que me faz querer dar o máximo de mim, em prol daquilo que acredito, isto é, retornar o meu conhecimento à sociedade. (Depoimento do bolsista F, maio 2011)

A dimensão da necessidade objetiva de manutenção dos próprios estudos, vivenciada por grande parte dos estudantes de licenciatura, está também presente entre os bolsistas do projeto e é uma realidade demonstrada pelo depoimento anterior.

Cabe salientar que há limitações para o exercício da interculturalidade como proposta educativa, na medida em que esta se depara com um contexto histórico-político contrário aos seus princípios.

A interculturalidade requer um contexto democrático ativo e real, que permita a igualdade de condições para todos os atores e que supere as limitações e as ambiguidades da democracia formal. (MARÍN, 2010, p. 325)

No subprojeto pedagogia na formação de professores em nivel médio, entre os nove bolsistas do PIBID que responderam ao questionário, dois indicaram desenvolver seu trabalho com o setor de coordenação pedagógica da escola e sete atuam com o projeto de dependência curricular em disciplinas do núcleo comum da formação de professores. 0 trabalho junto à coordenação pedagógica da escola, parceira nesse subprojeto, implica o acompanhamento de atividades como supervisão de estágios e de provas, organização de documentos e distribuição de atividades na escola. 0 trabalho do projeto de dependência envolve a atuação com estudantes do magistério que possuem a necessidade de revisar conhecimentos específicos propostos pela escola.

Perguntados sobre quais conhecimentos de sua formação profissional mais contribuem para o trabalho realizado na escola, os bolsistas fızeram algumas referências às disciplinas de avaliação e currículo, didática, gestão e planejamento escolar. Os bolsistas desse subprojeto apresentaram um discurso quase homogêneo em torno dos saberes cotidianos e das redes de relação entre os conhecimentos como centrais no trabalho desenvolvido. 0 depoimento da bolsista A2 exemplifica:

Os conhecimentos de minha formação profissional que mais contribuem são valorizar e perseguir práticas emancipatórias, críticas, participativas e dinâmicas, compreendendo a importância disso para o processo de formação tanto dos alunos como na configuração de minha identidade de futura professora. Acredito que isso está ligado ao referencial epistemológico metodológico usado no grupo de pesquisa [...] e em algumas propostas curriculares da universidade que compreendem a escola como espaço-tempo de formação para além do discurso hegemônico - fracasso escolar, provas únicas, currículos exclusivamente prescritos. Assim, o trabalho do grupo [no projeto da universidade] está pautado na valorização das práticas e trabalhos que já existem na escola, construindo uma parceria deste com 
esse espaço de formação. Dessa forma meu trabalho na escola é desenvolvido partindo da perspectiva de ver o aluno, os professores e funcionários sujeito de saberes, assim construímos nosso conhecimento em redes. (Depoimento, maio 2011)

Mais uma vez, a perspectiva de perceber a escola como espaço de saberes múltiplos, seus alunos, professores e funcionários como portadores de experiências importantes no processo de formação parece-nos remeter ao conceito de interculturalidade. Quanto ao questionamento sobre as contribuições do projeto para a formação profissional desses bolsistas, os depoimentos salientam a dimensão de pesquisa do PIBID e a integralidade da formação teórico-prática:

0 PIBID representa um amadurecimento dos meus estudos da educação e a solidificação do respeito aos estudos do cotidiano. As reuniões de pesquisa são pontos de encontro de experiência, saberes, dúvidas e conhecimentos; tempo em que podemos refletir e discutir a prática pedagógica. Além de todo o conhecimento que tecemos ao longo do projeto, o PIBID me permitiu conhecer melhor algumas dinâmicas do âmbito acadêmico, fazendo-me conhecer outras pesquisas e me preparando para estudos posteriores. (Depoimento do bolsista C1, maio 2011)

Considerando-se os 21 depoimentos analisados, foi possível observar que, com diferentes aproximações entre o espaço de formação na universidade e o espaço de formação na escola, todos os envolvidos como bolsistas de graduação têm indicado o PIBID como espaço de formação para a profissão de professor e como espaço de ampliação das aprendizagens dessa profissão.

A forma como os bolsistas de graduação referem-se aos conhecimentos aprendidos no projeto indica a possibilidade de integração entre os saberes aprendidos na academia e os saberes aprendidos na experiência com a escola e aponta a relevância desse projeto no âmbito da formação de professores. Além disso, destaca-se a não existência de um único saber, o que nos parece ser a contribuição fundamental da interculturalidade.

\section{Primeiras conclusões}

Partindo do interesse em refletir sobre as relações entre concepções de conhecimento escolar e formação de professores no âmbito do Programa Institucional de Bolsa de Iniciação à Docência (PIBID), propusemos, por meio do conceito de interculturalidade, discutir as percepções de conhecimento presentes entre os bolsistas de um projeto desenvolvido na universidade. Para isso, apresentamos a forma como têm funcionado os subprojetos pedagogia nos anos iniciais do ensino fundamental, licenciatura em ciências e pedagogia na formação de professores em nível médio, envolvendo 36 bolsistas de graduação, seis bolsistas supervisores do projeto em escolas públicas e três coordenadores de subprojeto de área na universidade, além do coordenador institucional do projeto.

Com base em um questionário aplicado aos bolsistas de graduação em maio de 2011 e no acompanhamento dos subprojetos em 2010/2011, questionou-se o que o PIBID tem representado em termos de formação integral do professor, considerando-se os saberes da prática profissional e os saberes acadêmicos como teórico-práticos em sua essência.

Percebeu-se que, no subprojeto pedagogia nos anos iniciais do ensino fundamental, as bolsistas de graduação conseguem, por meio do trabalho desenvolvido, integrar não apenas os saberes universitários aos fazeres docentes, mas também os saberes dos estudantes das escolas ao conteúdo trabalhado no espaço escolar, o que parece ser uma aprendizagem importante quando se considera a tradição docente de separar e desvalorizar os saberes da experiência dos alunos dos saberes propostos pela escola. 
Ao analisar os questionários dos bolsistas de graduação do subprojeto de licenciatura em ciências, também se pôde perceber uma relação entre os saberes acadêmicos e o fazer docente desenvolvido por meio do PIBID. Porém, ao menos no discurso apresentado, essa integração aparece na relação com o saber específico da disciplina de ciências e com pouca articulação na formação mais geral dos alunos da escola. Nesse grupo de bolsistas, apenas um depoimento divergiu dessa forma de ver os conteúdos de ciências.

Os bolsistas de graduação do subprojeto pedagogia na formação de professores em nivel médio destacam o caráter de pesquisa do projeto e a relação de algumas disciplinas do curso de pedagogia com o cotidiano escolar do qual participam. Não há uma referência mais específica aos conhecimentos trabalhados com as/os estudantes do nível médio de formação de professores que permita avaliar a integração entre as experiências desses estudantes e 0 conteúdo trabalhado pelos bolsistas do PIBID desse subprojeto na escola; tal questão será analisada na continuidade de nossa investigação. Também nessa próxima etapa da pesquisa, pretendemos investigar as perspectivas das coordenadoras dos subprojetos de área e, na possibilidade de continuidade do projeto, a visão que as escolas envolvidas têm sobre o PIBID, em especial, suas interlocuções com a universidade por meio do projeto.

Entendendo o PIBID como um projeto de ação-reflexão-ação (FREIRE, 2005) da prática escolar de forma integrada às práticas de formação na universidade, e compartilhando dessa mesma metodologia para a análise sobre as concepções de conhecimento presentes em tais práticas, concluímos que o referido programa, no contexto do projeto desenvolvido na universidade - campo de nosso estudo -, tem contribuído para intensificar as perspectivas interculturais no trato do conhecimento escolar, especialmente ao problematizar as práticas que, orientadas pelo princípio da neutralidade dos conhecimentos, destituem esses conhecimentos de suas funções políticas, so- ciais e culturais, tornando-os sem sentido em grande parte do tempo de formação, seja na escola ou na universidade.

Do ponto de vista da interculturalidade, que se preocupa com a destituição do caráter homogêneo dos conhecimentos trabalhados, os depoimentos parecem indicar certa relação entre as necessidades objetivas do cotidiano escolar, vivenciado por meio do desenvolvimento desse projeto, e os estudos de algumas disciplinas na universidade, notadamente, didática, currículo e avaliação.

Retomando a perspectiva inicial da pesquisa, entende-se que a concepção de conhecimento trabalhada na universidade e na escola pública tem oscilado entre perspectivas conservadoras (que compreendem o conhecimento como neutro e objetivo, sendo decorrentes do processo que toma um particular como universal) e perspectivas emancipatórias (aquelas que, compartilhando do conceito de bem viver, integram-se às necessidades dos grupos com os quais se trabalha). No que entendemos como perspectivas emancipatórias, o conhecimento é compreendido de forma relacional - pois é produzido considerando determinado contexto e decorre de saberes disponíveis em certa situação -, correspondente ao que é possivel compreender e aprender diante das relações estabelecidas, e complementar, na medida em que não temos um conhecimento que baste a determinada situação ou necessidade, mas um conjunto de conhecimentos que se complementam diante das questões que pretendemos compreender (WALSH, 2009).

Nesse sentido, os depoimentos dos bolsistas de graduação demonstram definições de conhecimento subjacentes ao entendimento de que não existiria um conhecimento a ser definido a priori em relação às situações educativas, mas sim um conhecimento que precisa ser articulado nessas situações, isto é, um conhecimento a ser identificado, definido e trabalhado na prática escolar (das escolas envolvidas e com os conhecimentos acadêmicos propostos pela universidade). Essa compreen- 
são concede ao projeto em questão especial relevância como instrumento de promoção da formação profissional do professor em uma perspectiva integral.

Tal formação é primordial, pois, para além dos aspectos teórico-metodológicos, é preciso colaborar com a formação de um profissional da educação capaz de se colocar na situação dos outros, exigindo uma experiência existencial que permita "construir a intercultu- ralidade como uma realidade do campo educativo" (MARÍN, 2010, p. 324). Mas, para tanto, é preciso "sair das próprias certezas e das verdades construídas a partir do pensamento hegemônico" (AZIBEIRO; FLEURI, 2010, p. 286) de que a sociedade brasileira é racialmente democrática, de que a escola trata a todos de forma igualitária e de que bastam as vontades individuais para tudo se resolver. 0 diálogo das culturas requer o desejo e o fazer coletivos.

\section{Referências}

APPLE, Michael. Educação e poder. Porto Alegre: Artes Médicas, 1989.

AZIBEIRO, Nadir Esperança; FLEURI, Reinaldo Matias. Paradigmas culturais emergentes na educação popular. In: GARCIA, Regina Leite (Org.). Diálogos cotidianos. Petrópolis: DP e Alii; Rio de Janeiro: FAPERJ, 2010. p. 276-296.

BRASIL. Lei n 10.639, de 09 de janeiro de 2003. Altera a Lei n 9.394, de 20 de dezembro de 1996, que estabelece as diretrizes e bases da educação nacional, para incluir no currículo oficial da Rede de Ensino a obrigatoriedade da temática "História e Cultura Afro-Brasileira", e dá outras providências. Diário Oficial da União, Brasília, DF, 10 jan. 2003.

BRASIL. Diretrizes Curriculares Nacionais para a Educação das Relações Étnico-Raciais e para o Ensino de História e Cultura Afro-brasileira e Africana. Brasília, DF: Ministério da Educação, 2005.

FREIRE. Paulo. Pedagogia do oprimido. 2. ed. Porto: Afrontamento; Ed. João Barrote, 1972. cap. III, p. 109-170.

GIMENO SACRISTÁN, José; PÉREZ GÓMEZ, Angel. Compreender e transformar o ensino. Tradução de Ernani F. da Fonseca Rosa. 4. ed. Porto Alegre: ArtMed, 1998. cap. 6-9, p. 119-293.

MARÍN, José. Dimensão histórica da perspectiva intercultural, educação, Estado e sociedade. In: GARCIA, Regina Leite (Org.) Diálogos cotidianos. Petrópolis: DP e Alii; Rio de Janeiro: FAPERJ, 2010. p. 313-330.

PIMENTA, Selma G.; LIMA, Maria do Socorro L. Estágio e docência. 5. ed. São Paulo: Cortez, 2010.

WALSH, Catherine. Interculturalidad, estado, sociedad: luchas (de)coloniales de nuestra época. Quito: Universidad Andina Simón Bolívar, Ediciones Abya-Yala, 2009.

Recebido em: 30.11.2011

Aprovado em: 13.03.2012

Andréa Rosana Fetzner é professora no Programa de Pós-Graduação em Educação e no Departamento de Didática da Universidade Federal do Estado do Rio de Janeiro (UNIRIO). É organizadora da coletânea Ciclos em Revista, pela WAK Editora.

Maria Elena Viana Souza é professora na Universidade Federal do Estado do Rio de Janeiro (UNIRI0), atuando no Programa de Pós-Graduação em Educação e no Departamento de Didática. Organizou recentemente o livro Relações raciais no cotidiano escolar: diálogos com a Lei 10.639/03, publicado pela Editora Rovelle. E-mail: mevsouza@yahoo.com.br. 